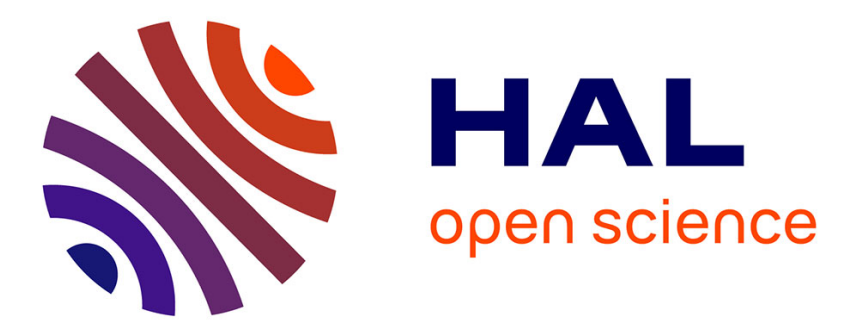

\title{
Activities by Hediste diversicolor under different light regimes: experimental quantification of particle reworking using time-resolved imaging
}

\author{
Stina Lindqvist, Franck Gilbert, Susanne Eriksson, Stefan Hulth
}

\section{To cite this version:}

Stina Lindqvist, Franck Gilbert, Susanne Eriksson, Stefan Hulth. Activities by Hediste diversicolor under different light regimes: experimental quantification of particle reworking using time-resolved imaging. Journal of Experimental Marine Biology and Ecology, 2013, vol. 448, pp. 240-249. 10.1016/j.jembe.2013.06.014 . hal-00875693

\section{HAL Id: hal-00875693 https://hal.science/hal-00875693}

Submitted on 8 Nov 2013

HAL is a multi-disciplinary open access archive for the deposit and dissemination of scientific research documents, whether they are published or not. The documents may come from teaching and research institutions in France or abroad, or from public or private research centers.
L'archive ouverte pluridisciplinaire HAL, est destinée au dépôt et à la diffusion de documents scientifiques de niveau recherche, publiés ou non, émanant des établissements d'enseignement et de recherche français ou étrangers, des laboratoires publics ou privés. 


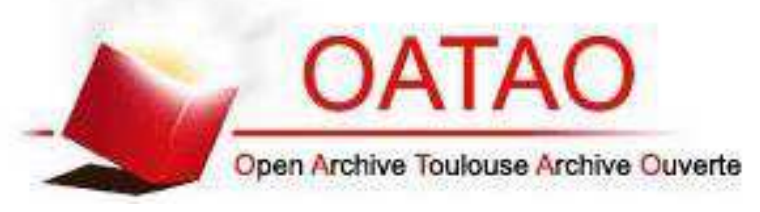

\section{Open Archive TOULOUSE Archive Ouverte (OATAO)}

OATAO is an open access repository that collects the work of Toulouse researchers and makes it freely available over the web where possible.

This is an author-deposited version published in : http://oatao.univ-toulouse.fr/ Eprints ID : 9565

To link to this article : DOI:10.1016/j.jembe.2013.06.014 URL : http://dx.doi.org/10.1016/j.jembe.2013.06.014

To cite this version : Lindqvist, Stina and Gilbert, Franck and Eriksson, Susanne and Hulth, Stefan Activities by Hediste diversicolor under different light regimes: experimental quantification of particle reworking using time-resolved imaging. (2013) Journal of Experimental Marine Biology and Ecology, vol. 448 . pp. 240-249. ISSN 0022-0981

Any correspondance concerning this service should be sent to the repository administrator: staff-oatao@,listes-diff.inp-toulouse.fr 


\title{
Activities by Hediste diversicolor under different light regimes: Experimental quantification of particle reworking using time-resolved imaging
}

\author{
Stina Lindqvist ${ }^{\text {a }}$, Franck Gilbert ${ }^{\text {b,c }}$, Susanne P. Eriksson ${ }^{\mathrm{d}}$, Stefan Hulth ${ }^{\mathrm{a}, *}$ \\ a Department of Chemistry and Molecular Biology, University of Gothenburg, 41296 Göteborg, Sweden \\ ${ }^{\mathrm{b}}$ Université de Toulouse III, UPS, INP, EcoLab (Laboratoire d'écologie fonctionnelle et environnement), Bt. 4R1, 118 route de Narbonne, F-31062 Toulouse CEDEX 9, France

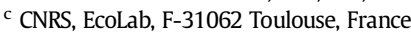 \\ d Department of Biological and Environmental Sciences - Kristineberg, University of Gothenburg, Kristineberg 566, SE-451 78 Fiskebäckskil, Sweden
}

Keywords:

Bioturbation

Gallery-diffusor

Hediste diversicolor

Luminophores

Sediment reworking

Time-resolved imaging

\begin{abstract}
a b s t r a c t
Particle reworking by the ragworm Hediste diversicolor was assessed by quantifying the transport of fluorescent particles (luminophores) added to the surface sediment during a 10 day experiment. Plexiglass cores and thin glass aquaria with fauna and controls were exposed to either 12 hour light/dark cycles or constant darkness. Luminophore distributions were evaluated by side-view imaging of the aquaria together with destructive sectioning and quantification of tracer distributions in both types of microcosms at the end of experiments. Tracer distributions were evaluated by the gallery-diffusor model, from which the biodiffusion $\left(D_{b}\right)$ and the non-local transport ( $r$ ) coefficients were determined. In addition, the maximum penetration depth (MPD) of luminophores, the 2-D redistribution coefficient, and the transport rate were used as a suite of proxies to quantify particle reworking by fauna.

All measured reworking proxies demonstrated a general decrease in transport of luminophores in darkness compared to light/dark cycles. The difference was significant for proxies determined from sectioning. Imaging of particle transport demonstrated that rates were $\sim 30 \%$ higher during light/dark cycles, with $\sim$ constant amount of particles transported on a daily basis. The effect of light was consistent in the two microcosm types. However, there was a significant difference in $\mathrm{D}_{\mathrm{b}}$, while $\mathrm{r}$ and MPD were not significantly different between the cores and aquaria. Overall, these results suggest a light-triggered surface feeding by $\mathrm{H}$. diversicolor. Our study highlights the importance of experimental settings for quantification of particle transport by fauna, and that light conditions and types of experimental microcosms need to be carefully considered during investigations of bioturbation in illuminated environments.
\end{abstract}

\section{Introduction}

Benthic macrofauna significantly influences early diagenesis and the fate of organic material deposited on the sediment surface. Faunal activities not only alter the physical geometry and biogeochemical structure of the sediment, but also affect the transport of particles, solutes and gases across the sediment water interface and across redox boundaries within the sediment (Aller, 1994; Rhoads, 1974). This is done mainly by redistributing material during e.g. feeding, burrowing, ventilation, tube construction, and fecal pellet formation (Aller, 1982; Kristensen et al., 2012). It is therefore essential to quantify particle and solute mixing induced from bioturbating fauna and to include faunal reworking activities in qualitative and quantitative models describing biogeochemistry and element cycling in surface sediments. Reworking parameters for particle transport by fauna are

\footnotetext{
* Corresponding author. Tel.: +46317869024.

E-mail address: stefan.hulth@chem.gu.se (S. Hulth).
}

normally extracted from experimental quantification of the vertical distribution of tracers and subsequent reaction-transport modeling (Aller, 1982; Berner, 1980; Boudreau, 1997). The most frequently applied model for particle transport relies on the biodiffusive approach in which the conservation of mass and Fick's first law of diffusion are combined into the biodiffusion coefficient, $D_{b}$ (Boudreau, 1986; Goldberg and Koide, 1962; Guinasso and Schink, 1975). The underlying theoretical assumptions in the biodiffusion model have recently been reevaluated and partly revised (Meysman et al., 2010). Despite that model constraints are often violated (Lecroart et al., 2010; Wheatcroft et al., 1990), tracer distributions obtained from the biodiffusion model are frequently in close accordance with those obtained from direct measurements (Meysman et al., 2003). Models for particle reworking have occasionally been modified to also include biological transport of particles in a non-diffusive manner. Such modifications are referred to as the non-local transport or anomalous reworking (Fisher et al., 1980; Meysman et al., 2010; Smith et al., 1986). Francois et al. $(1997,2002)$ have developed a suite of 
models that couple to the reworking modes of individual species. Of these, above all the gallery-diffusor model (François et al., 2002) has successfully been applied to evaluate reworking activities by Hediste diversicolor (Duport et al., 2006; Mermillod-Blondin et al., 2004). The rapid transport of particles from the sediment surface to deeper sediment layers is estimated by the non-local transport coefficient, $r$, while the diffusive-like transport in surface sediments is estimated by the biodiffusion coefficient, $D_{b}$.

A vast majority of previous experiments designed to assess particle reworking activities by $\mathrm{H}$. diversicolor have integrated particle reworking over the experimental period (often 10 to 30 days). In these studies, the vertical distributions of tracers were mainly quantified by manual efforts following sectioning of sediment cores in discrete sediment layers with inherent destructive sampling protocols (Duport et al., 2006; François et al., 2002; Hedman et al., 2011). Therefore, the temporal evolution of reworking parameters (or proxies) is normally excluded and not quantified. Gilbert et al. (2003) developed a technique for 2-dimensional experimental quantification of particle displacement by fauna using side-view imaging of fluorescent particles (luminophores). With the non-destructive side-view imaging of luminophores emerging as a complementary technique to estimate particle reworking, there is also a potential for high-resolution (temporal and spatial) studies of bioturbation activities by benthic macrofauna (Maire et al., 2008; Schiffers et al., 2011). A number of bioturbation experiments have since been conducted using concepts originating from the fluorescence imaging approach (Maire et al., 2006; Piot et al., 2008; Schiffers et al., 2011), including imaging of faunal activities in situ (Solan et al., 2004). However, the thin aquaria used for imaging experiments may bias quantification of reworking proxies. Potential artifacts associated with experimental settings include e.g. alterations in reworking behavior due to wall effects and the physical geometry of the microcosm. To our knowledge, there is no previous study that quantifies and compares reworking proxies in cores and aquaria.

The common ragworm $\mathrm{H}$. diversicolor (Polychaeta, Nereididae), normally classified as a gallery-diffusor in terms of mode of particle reworking (François et al., 2002), is a frequently used model species for experimental studies of bioturbation by benthic macrofauna. The polychaete is commonly found in marine and brackish waters of the littoral zone across the Atlantic coasts of North America and Europe (Scaps, 2002). H. diversicolor has during several studies been demonstrated as a major bioturbator with significant influence on the biogeochemical structure, function, and dynamics of surface sediments. For example, bioturbating activities by $\mathrm{H}$. diversicolor may have considerable, but often not easily predicted, effects on organic matter cycling and nutrient fluxes in shallow-water sediments (Kristensen et al., 1992; Nizzoli et al., 2007; Papaspyrou et al., 2010). In addition, activities by $\mathrm{H}$. diversicolor may have significant effects on phytoplankton production (Vedel et al., 1994), as well as on the initiation, growth and sustenance of macroalgal mats and seagrass beds in shallowwater embayments (Hughes et al., 2000; Nordström et al., 2006).

There are several environmental factors that affect the behavior of $\mathrm{H}$. diversicolor and thereby also the magnitude and extent of bioturbation. Availability of food supply (Nogaro et al., 2008; Papaspyrou et al., 2010), tidal cycles (Esselink and Zwarts, 1989) and availability of light (Lambert et al., 1992; Tang and Kristensen, 2007; Wenzhöfer and Glud, 2004) provide examples that have been included in studies focused on the behavior of $\mathrm{H}$. diversicolor. Investigations that specifically describe how the availability of light affects bioturbation and sediment reworking by $\mathrm{H}$. diversicolor have up to now concentrated on the shortterm (24 $36 \mathrm{~h}$ ) behavior during feeding (Lambert et al., 1992), the oxygen uptake (Wenzhöfer and Glud, 2004) and the benthic metabolism (Tang and Kristensen, 2007).

The overall aim of the study was to quantify particle displacement by $\mathrm{H}$. diversicolor using the non-destructive fluorescence imaging approach and the destructive manual sectioning technique. Imaging was primarily used for high resolution quantification of reworking proxies in both time and space. Specific objectives were to investigate how experimental proxies for particle reworking were affected by 1) the exposure of $\mathrm{H}$. diversicolor to constant darkness as compared to $12 \mathrm{~h}$ light/dark cycles, and 2) sediment water incubations in thin glass aquaria as compared to incubations in Plexiglass cores.

\section{Materials and methods}

\subsection{Experimental design and general overview}

In this tracer-pulse experiment, the effects of i) light/dark cycles compared with constant darkness (statistical factor Light) and ii) Plexiglass cores compared with glass aquaria (statistical factor Microcosm ) on particle reworking activities by $\mathrm{H}$. diversicolor were investigated in a factorial design. Individuals of $\mathrm{H}$. diversicolor were added to microcosms (Plexiglass cores $(\mathrm{C})$ or thin glass aquaria (A)) and were either exposed to $12 \mathrm{~h} \mathrm{light/dark} \mathrm{cycles} \mathrm{(Li/Da),} \mathrm{or} \mathrm{to}$ constant darkness (Dark) $(\mathrm{n}=6)$. There were also corresponding control treatments without fauna added $(n=6)$.

Particle displacement was evaluated from vertical profiles obtained by sectioning of sediment and modeling (François et al., 2002) $(n=6)$ and from time-resolved imaging of the fluorescent particles in thin aquaria (Gilbert et al., 2003) ( $\mathrm{I} ; \mathrm{n}=3$ ). In addition to $\mathrm{D}_{\mathrm{b}}$, $\mathrm{r}$ and maximum penetration depth of luminophores (MPD) (Maire et al., 2006), the fluorescence imaging approach provided bioturbation proxies associated with 2-D redistribution, and transport rates.

\subsection{Sampling and set-up}

Surface sediment $(05 \mathrm{~cm}$ ) and $\mathrm{H}$. diversicolor were sampled by hand from a shallow bay on the Swedish west coast (Rågårdsvik, N 58 $12^{\prime} 32^{\prime \prime}$; E $11^{\circ} 26^{\prime} 47^{\prime \prime}$ ) in May 2007 (Table 1). The sampling area is microtidal with an average tidal amplitude of $\sim 20 \mathrm{~cm}$ and a salinity between 20 and 25 (Pihl and Rosenberg, 1982). The sampling area has been described as silty and semi-enclosed with high organic matter content and high porosity in the surface sediment. The benthic macrofaunal community is dominated by detrivores (Engelsen et al., 2008).

Porosity was measured at the sampling occasion by weight loss after drying the sediment at $70{ }^{\circ} \mathrm{C}$ until constant weight. Solid phase organic carbon (TOC) and organic nitrogen (TON) were determined by an elemental analyzer NA 1500 NC, Fison instruments Grain size was determined by sieving and re-weighing a known amount of dry sediment through a stack of sieves with progressively decreasing mesh size. The analysis on dry sediment may have underestimated the silt and clay fraction due to particle aggregation during the drying process.

Sediment and fauna were transported to temperature-controlled $\left(15^{\circ} \mathrm{C}\right)$ facilities at the Lovén Centre Kristineberg. The sediment was dry-sieved $(1 \mathrm{~mm})$ to remove macrofauna and larger debris, homogenized, and placed in large $(75 \times 55 \times 45 \mathrm{~cm})$ plastic containers. Animals were placed in sediment from the sampling location. Sediment and animal aquaria were continuously supplied with unfiltered seawater from the Gullmarsfjord $\left(\mathrm{S}=31, \mathrm{~T}=15^{\circ} \mathrm{C}\right)$ for a period of 11 days to stabilize biogeochemical characteristics and chemical

Table 1

Overview of experimental activities.

\begin{tabular}{|c|c|}
\hline Day & Activity \\
\hline $23 / 24$ & Sampling of animals and sediment \\
\hline 14 & $\begin{array}{l}\text { Plexiglass cores inserted into the sediment and thin aquaria filled } \\
\text { with sediment }\end{array}$ \\
\hline 7 & Additions of Hediste diversicolor to the experimental microcosms \\
\hline 01 & Additions of luminophores and start of sediment water incubations \\
\hline 111 & Capture of images \\
\hline 1011 & Termination of incubation \\
\hline
\end{tabular}


gradients in the sediment pore water system before Plexiglass cores $(\emptyset=10 \mathrm{~cm}$, height $=30 \mathrm{~cm})$ were carefully inserted into the sieved sediment $(\sim 14 \mathrm{~cm}$ deep). In parallel, sieved sediment (height $\approx 14 \mathrm{~cm}$ ) and bottom water from the sampling location were added to thin glass aquaria $(16 \times 33 \times 1.4 \mathrm{~cm})$. The overlying water was replaced regularly and each microcosm was continuous aerated by aquaria pumps.

$\mathrm{H}$. diversicolor was introduced seven days after sediment was added to cores and aquaria. Individuals were wet weighed (ww) and the volume of each animal was measured using a graded measuring cylinder before the addition. Faunal density was 530 ind. $\mathrm{m}^{2}$ in the cores (4 individuals) and 446 ind. $\mathrm{m}^{2}$ in the aquaria (1 individual). This is within the lower range typically observed on the Swedish west coast (35 3700 ind. $\mathrm{m}^{2}$; Scaps, 2002). The biomass varied between 58 and $71 \mathrm{~g} \mathrm{ww} \mathrm{m}{ }^{2}$ in the cores and between 28 and $41 \mathrm{~g} \mathrm{ww} \mathrm{m}^{2}$ in the aquaria, and the biovolume ranged between 66 and $200 \mathrm{~mL} \mathrm{~m}{ }^{2}$ in the cores and between 110 and $170 \mathrm{~mL} \mathrm{~m}{ }^{2}$ in the aquaria. All animals burrowed within $25 \mathrm{~min}$, a majority (N70\%) within $10 \mathrm{~min}$. The Li/Da and Dark treatments started at the addition of fauna. Microcosms were either exposed to $12 \mathrm{~h}$ light/dark cycles $\left(\sim 8 \mu \mathrm{mol}\right.$ photons $\left.\mathrm{m}^{2} \mathrm{~s}^{1}\right)$, or to constant darkness (covered with opaque black plastic).

$\mathrm{H}$. diversicolor was allowed to acclimate for another week in the experimental set-up before luminophores were added and image acquisition started. At the start of tracer incubations, fluorescent particles (Partrac; $63125 \mu \mathrm{m}, \lambda_{\mathrm{ex}}=500 \mathrm{~nm}, \lambda_{\mathrm{em}}=602 \mathrm{~nm}$ ) were dispensed into the overlying water of the aquaria to a final density of $\sim 265 \mathrm{~g}$ luminophores $\mathrm{m}^{2}$. Image acquisition started when the luminophores had settled on the sediment surface. In total, 32 images were captured of each aquarium, of which 17 were used for evaluation of reworking proxies. Images for quantification of particle transport were evaluated on a daily basis for all proxies, while more frequently at the beginning of the experiment for the 2-D redistribution $(4,8,12,24$ and $36 \mathrm{~h})$. The experimental period of the sediment water incubations with luminophores was 10 days.

\subsection{Optical instrumentation and image analysis}

In brief, the optical set-up included a $300 \mathrm{~W}$ xenon lamp used as light source for luminophore excitation. The excitation wavelength was obtained by a bandpass filter (Thorlabs; $510 \mathrm{~nm} \pm 10 \mathrm{~nm}$ ) mounted on-line with the light source. Fluorescence emission was captured by a Canon EOS 350D digital (CMOS image sensor) camera with a bandpass filter (Thorlabs; $610 \mathrm{~nm} \pm 10 \mathrm{~nm}$ ) mounted on-line with the CMOS chip. The aquaria were manually positioned in front of the camera during experiments and image acquisition was controlled from an adjacent room.

All images were captured in the RAW (.CR2) format with a $3456 \times 2304$ pixel resolution (corresponds to $\sim 8 \mathrm{M}$ pixels), saved in Exef-TIFF ( 8 bit, Digital Photo Professional 2.2.0.1) and processed in Matlab7.5 (R2007B). The effective pixel size was $\sim 80 \mu \mathrm{m}$ pixel ${ }^{1}$. There was a need to re-align the images (pixel by pixel) prior to processing due to the manual positioning of the aquaria. This was done using the plugin TurboReg (Thevenaz et al., 1998) in the image processing program Image (Version 1.45).

Fluorescence was quantified using the red layer of the CMOS chip. Image threshold was obtained by maximizing visualization of luminophore fluorescence while simultaneously minimizing artifacts caused e.g. by reflections from the glass wall of the aquaria. The total fluorescence from luminophores varied with time for individual sets of aquaria, indicating non-conservative parameterization. The threshold value was therefore adjusted throughout the experimental period to maintain a stable total fluorescence and thereby correct for this apparent instability in mass conservation over time. By this procedure, variations in the total fluorescence narrowed from a range of 79 to $165 \%$ to a range of 91 to $102 \%$ compared to the initial fluorescence at the start of the experiment.
The position of the sediment water interface was determined in the resulting binary matrix. Before the analysis of $D_{b}, r$ and MPD, the sediment surface was flattened. During this process, each column was individually adjusted so that pixels corresponding to the sediment surface were in the first row (Solan et al., 2004). Prior to the quantification of 2-D redistribution and daily transport rates, pixels above the sediment water interface were set to 0 in order to remove artifactual fluorescence from luminophores attached to the glass wall of the aquaria. Compaction was compensated for by correcting the image matrix upwards at the same rate as compaction affected the sediment during the time between the images. This gravity-driven transport process of particles would otherwise artifactually contribute to these proxies, especially close to the sediment surface. Total compaction was estimated to $\sim 2 \mathrm{~mm}$ during the 10 day experiment.

\subsection{Quantification of reworking proxies}

The Optical Reworking Coefficient (ORC) was initially described by Gilbert et al. (2003). A slightly modified approach was used in this work and three other reworking proxies were derived from images. The basic idea was similar, i.e. the binary image obtained at time $t\left(M_{t}\right)$ was subtracted from the binary image at the start of experiments $\left(\mathrm{M}_{0}\right)$. The sum of the resulting matrix $M$ therefore described the total relocation of luminophores in the sediment. In our study, no further modeling was performed and results were directly presented as a function of incubation time. In contrast to the ORC, absolute values of pixels (|X|) were summed and results were not normalized for time.

The 2-D redistribution was calculated from the binary image obtained at time $t\left(\mathrm{M}_{\mathrm{t}}\right)$, subtracted from the binary image at the start of experiments $\left(\mathrm{M}_{0}\right)$. A daily particle transport was calculated from the binary image obtained at time $t\left(M_{t}\right)$, subtracted from the binary image captured the previous day $\left(M_{t} 24 \mathrm{~h}\right)$. The integrated transport $\left(\sum \mathrm{M}_{\mathrm{i}}\right)$ was obtained by adding the daily transport to the total sum of particle displacements from previous days of incubation. The derivative of the integrated transport over time $\left(\delta \sum \mathrm{M}_{\mathrm{i}} / \delta \mathrm{t}\right)$ described the rate of luminophore transport $\left(\mathrm{cm}^{2} \mathrm{~d}^{1}\right)$. For the maximum penetration depth of luminophores (MPD), seven pixels with a positive fluorescence response were set as the detection limit to exclude background noise.

In addition to quantification of luminophore tracers by means of side-view imaging, luminophore distributions were assessed by sectioning and counting of the tracer. At the termination of the experiment, cores and aquaria were sectioned in $0.5 \mathrm{~cm}$ layers down to $2 \mathrm{~cm}$, and in $1 \mathrm{~cm}$ layers down to the bottom of the microcosm $(1213 \mathrm{~cm})$. The sediment from each section was homogenized, a subsample collected and freeze-dried. Quantification of luminophores was made under UV-light using a Synergy Mx microplate reader (Lagauzere et al., 2011).

The obtained distributions of luminophores were evaluated by the gallery-diffusor model (François et al., 2002). Two main mechanisms for particle transport are included in the model 1) diffusive mixing in the shallow sediment with dense burrows, and 2) non-local transport within burrows. The model is time- and space dependent and employs ordinary differential equations. The biodiffusion coefficient $\left(D_{b}\right)$ and the non-local transport coefficient $(r)$ were calculated by minimizing a weighted sum of squared differences between the observed and modeled tracer concentrations with depth in the sediment. The MPD was also determined from the vertical distributions of luminophores.

\subsection{Statistical analysis}

$D_{b}, r$, and the MPD determined from the sectioning method were evaluated by a two-way analysis of variance (ANOVA) for significant $(\alpha=0.05)$ differences between faunal treatments (Light and Microcosm). As the main focus in this work was to explore effects from light 
availability and the type of microcosm (i.e. not the technique for fluorescence evaluation per se) on particle reworking by $\mathrm{H}$. diversicolor, comparisons between the imaging technique and the slicing technique were not made for $D_{b}, r$ and MPD. Differences in the 2-D redistribution and the MPD at the termination of the incubation and the transport rate between the treatments Li/Da-I and Dark-I were tested with t-tests. Prior to analysis, assumptions of normality and homogeneity of variances were assessed by graphical exploration of box plots (Quinn and Keough, 2002). Homogeneity of variance was also evaluated with Levene's test. In order to homogenize variances $\mathrm{r}$ was $\log (\mathrm{x}+1)$ transformed and the MPD was $\log (\mathrm{x})$ transformed. Statistical analyses were performed with IBM SPSS Statistics for Windows (version 20.0)

\section{Results}

\subsection{General observations, recovery of fauna and sediment properties}

All faunal microcosms were affected by reworking at the time of luminophore addition. New burrows and sediment constructions were created progressively throughout the incubation. In addition to the perforation of the surface sediment with shallow $(\sim 12 \mathrm{~cm})$ burrows, there were burrows visible down to $\sim 5 \mathrm{~cm}$ depth. Burrows were preferentially observed along the side-wall of the aquaria in the thin aquaria. Control microcosms were devoid of larger burrow constructions. There were thin traces of burrows in the top $\mathrm{cm}$ of the sediment and occasional visual observations of a removal of luminophores from the sediment surface that indicated the presence of small fauna in control microcosms.

Upon termination of experiments, 41 of $48(\sim 85 \%)$ individuals were found in the cores and 11 of $12(\sim 92 \%)$ individuals were recovered in the aquaria. $\mathrm{H}$. diversicolor was mainly retrieved down to $\sim 5 \mathrm{~cm}$ depth, and a majority within the $1.54 \mathrm{~cm}$ sediment layer (Fig. 1). During sectioning of the aquaria, several individuals were observed burrowing downwards and were subsequently found at the bottom of the sediment column (10 $12 \mathrm{~cm}$ depth). However, as they were all initially recognized in the top $5 \mathrm{~cm}$, this observation was considered an escape reaction associated with the sectioning procedure and therefore an artifact related to the experimental protocol. Further, as the number of luminophores retrieved below $7 \mathrm{~cm}$ was negligible (see below), the artifactual downward movement of fauna upon sectioning seemed not to have affected the qualitative or quantitative interpretation of bioturbation activities by H. diversicolor.

The sediment was defined as silty sand with a grain size distribution of $44 \%$ silt and 52\% fine sand. The TOC of the sediment used for incubations was $1.8 \%$ and TON $0.16 \%$ at the start of the experiment. Sediment porosity in the cores at the termination of the experiment was $0.79 \pm 0.11(\mathrm{n}=6)$ in the $00.5 \mathrm{~cm}$ layer and $0.58 \pm 0.03$ $(\mathrm{n}=6)$ in the $1112 \mathrm{~cm}$ layer.

\subsection{Distribution of luminophores}

In the control microcosms, deposited luminophores were exclusively found in the top $\mathrm{cm}$ of the sediment. 98 99\% were observed in the $00.5 \mathrm{~cm}$ sediment layer (including the lower fraction of the bottom water just above the sediment surface), and $12 \%$ were recovered in the $0.51 \mathrm{~cm}$ layer by the sectioning technique. Close to $100 \%$ of the luminophores were found in the $00.5 \mathrm{~cm}$ layer by the imaging technique.

In contrast, luminophores were removed from the top sediment layer as a consequence of reworking activities by $\mathrm{H}$. diversicolor. In the light/dark cycles, $7289 \%$ of deposited luminophores were recovered in the first $0.5 \mathrm{~cm}$ of the sediment in the cores $(\mathrm{Li} / \mathrm{Da}-\mathrm{C})$ and $7288 \%$ in the aquaria ( $\mathrm{Li} / \mathrm{Da}-\mathrm{A})$. Under the dark conditions, 86 93\% were retrieved in the cores (Dark-C) and $9499 \%$ in the aquaria (Dark-A). Imaging of luminophore distributions demonstrated similar patterns of luminophore removal from the sediment surface: $6281 \%$ and $7395 \%$ of luminophores were found in the $00.5 \mathrm{~cm}$ sediment layer during light/dark (Li/Da-I) and dark (Dark-I) conditions, respectively. Further, observations of subsurface peaks of luminophores were less evident in the dark compared to the light/dark treatment (Fig. 2).

Similar patterns emerged when the MPD was examined at the termination of the experiment (Fig. 3). Luminophores were observed significantly deeper in the light/dark cycles (Li/Da-C, $6.3 \pm 1.3 \mathrm{~cm}$, and $\mathrm{Li} / \mathrm{Da}-\mathrm{A}, 6.8 \pm 2.9 \mathrm{~cm}$ ) compared to cores and aquaria exposed to constant darkness (Dark-C, $3.5 \pm 1.3 \mathrm{~cm}$, and Dark-A, $5.2 \pm 2.7 \mathrm{~cm}$ ). There was no significant difference in MPD between the microcosm treatments (2-way ANOVA, Table 2).

With the results from imaging, the evolution of MPD could be resolved in time. In the $\mathrm{H}$. diversicolor treatments luminophores were quickly (within a day) transported downwards to a depth in close accordance with the final MPD (Figs. 4 and 5). The MPD from image analysis at the termination of the experiment (10 days) supported the observed deeper penetration of luminophores under the light/dark (Li/Da-I, $2.8 \pm 1.6 \mathrm{~cm}$ ) compared to dark (Dark-I, $1.1 \pm$ $0.4 \mathrm{~cm}$ ) conditions, although the difference was not significant (t-test, $\mathrm{p}=0.147)$. The MPD in the controls was shallower $(0.4 \pm 0.1 \mathrm{~cm}$ for both light/dark and dark conditions) compared to that in the faunal aquaria.
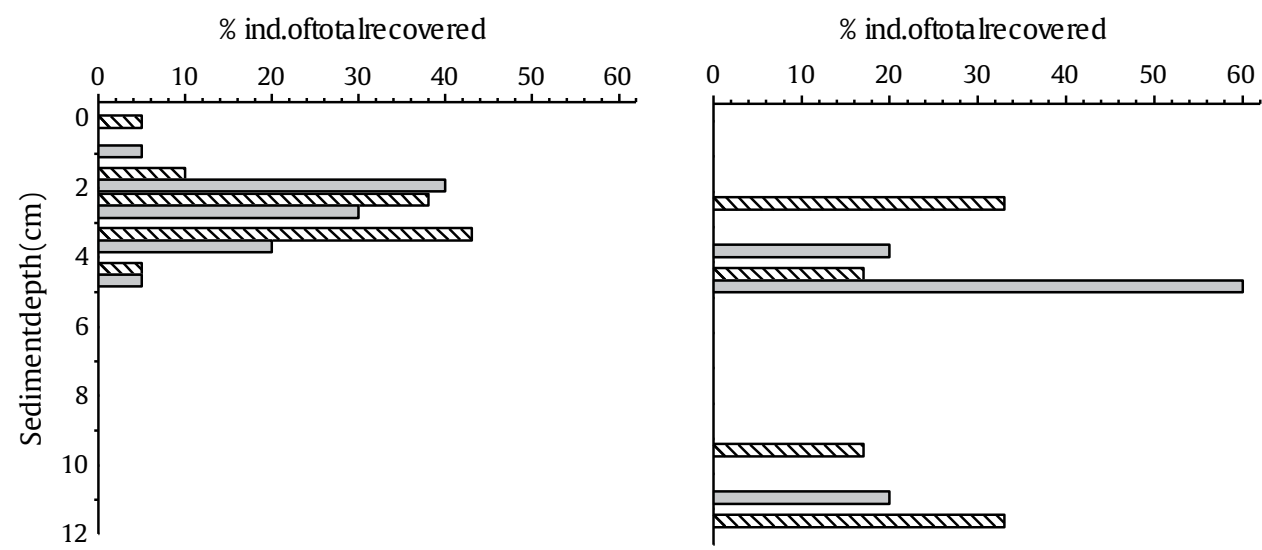

Fig. 1. Distribution of Hediste diversicolor recovered at the end of experiment in Plexiglass cores $($ left, $n=6)$ and thin aquaria (right, $n=6)$ incubated under light/dark (striped) and dark (filled) conditions. 
i)

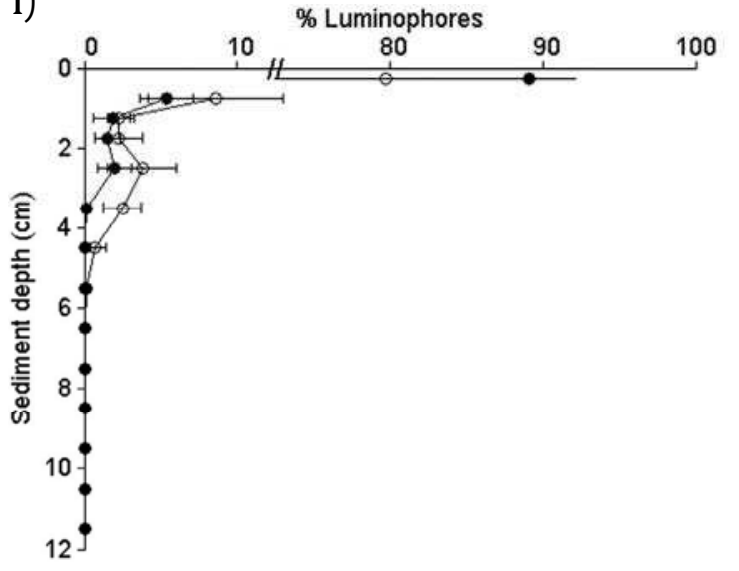

ii)

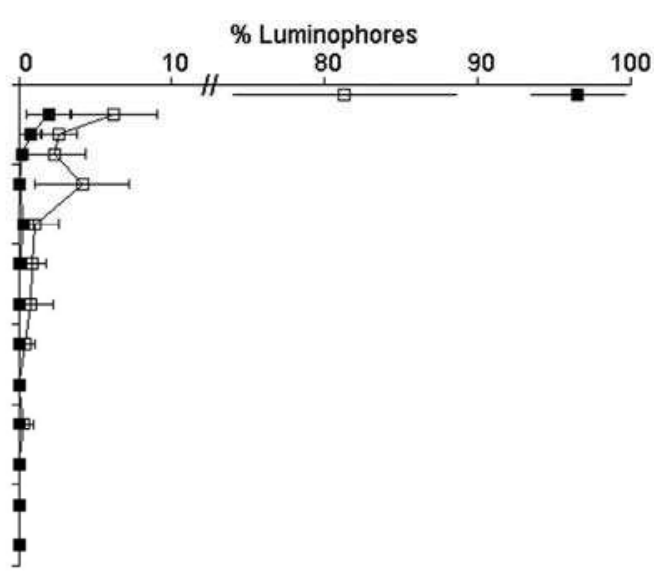

iii)

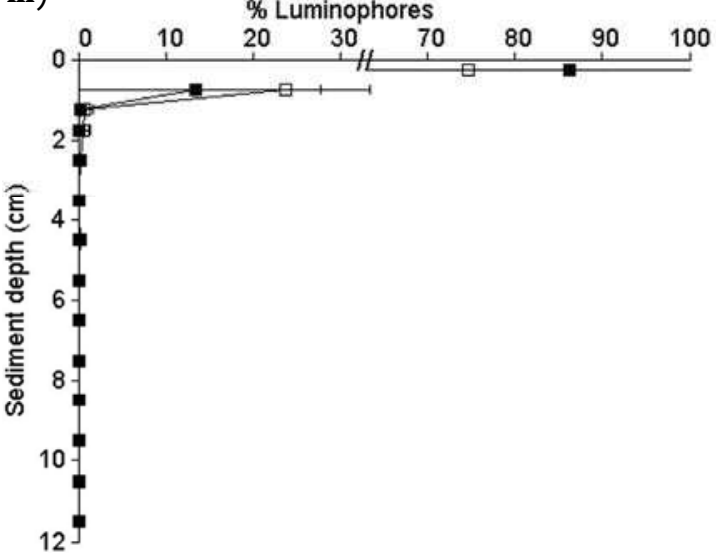

Fig. 2. Distribution of luminophores (mean $\pm \mathrm{SD}$ ) following incubations of sediment with Hediste diversicolor in Plexiglass cores $(\mathrm{i}, \mathrm{n}=6$ ) and thin aquaria (ii, $\mathrm{n}=6$ ) Distributions from using side-view imaging are also illustrated (iii, $n=3$ ). Experiments were performed under light/dark (open symbols) and dark (filled symbols) conditions. Note the different scales.

\subsection{Quantification of particle reworking by imaging}

The 2-D redistribution quantitatively described and visualized the temporal and spatial change in distribution of luminophores following bioturbation by H. diversicolor (Fig. 6). Over the whole experimental period, there was a logarithmic increase in 2-D redistribution with time of incubations. The logarithmic trend was more pronounced for the faunal treatments compared to the controls. During the initial $\sim$ two days of experiment, the 2-D change in luminophore distribution increased in a seemingly linear fashion for all aquaria (Li/Da-I, $0.83 \pm 0.21 \mathrm{~cm}^{2} \mathrm{~d}^{1}$, and Dark-I, $0.64 \pm 0.29 \mathrm{~cm}^{2} \mathrm{~d}^{1}$, linear fit). After this period, the increase in 2-D redistribution with time was less pronounced (Li/Da-I, $0.11 \pm 0.03 \mathrm{~cm}^{2} \mathrm{~d}^{1}$, and Dark-I, $0.10 \pm$ $0.05 \mathrm{~cm}^{2} \mathrm{~d}^{1}$, linear fit) compared to that observed within the first
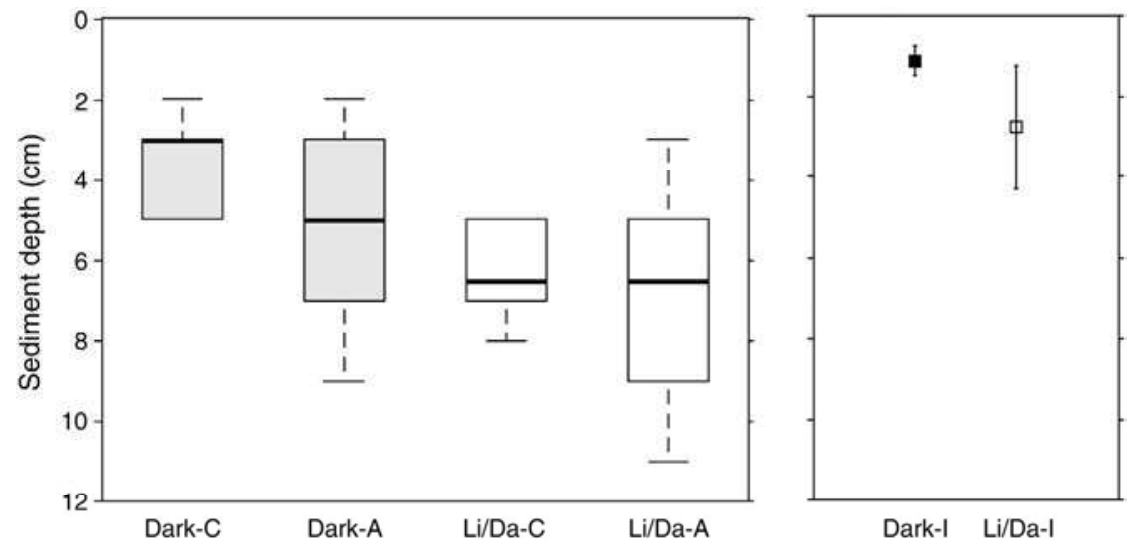

Fig. 3. Maximum penetration depth of luminophores (MPD) as a consequence from particle displacement by Hediste diversicolor during sediment water incubations in cores (C) and aquaria (A). Reworking activities were quantified by sectioning and semi-automatic counting of luminophore distributions (left) or from side-view imaging (I) of luminophore fluorescence in the aquaria (right). Incubations were performed under light/dark (Li/Da-C, Li/Da-A and Li/Da-I) and dark (Dark-C, Dark-A and Dark-I) conditions. Boxplots $(n=6)$ demonstrate the median and the 25th and 75th percentiles (edges of the box) of the data set. The whiskers extend to the most extreme data points. MPD quantified by the imaging technique is represented as mean $\pm \mathrm{SD}(\mathrm{n}=3)$. 
Table 2

Statistic analysis (two-way analysis of variance, ANOVA table) of the biodiffusion coefficient $\left(D_{b}\right)$, the non-local transport coefficient $(r)$ and the maximum penetration depth of luminophores (MPD). ${ }^{*}$ denotes differences significant at $\alpha=0.05$.

\begin{tabular}{|c|c|c|c|c|c|c|c|c|c|c|}
\hline \multirow[t]{2}{*}{ Source of variation } & \multirow[t]{2}{*}{ d.f. } & \multicolumn{3}{|l|}{$\mathrm{D}_{\mathrm{b}}$} & \multicolumn{3}{|l|}{$r$} & \multicolumn{3}{|l|}{ MPD } \\
\hline & & m.s & $\mathrm{F}$ & $\mathrm{p}$ & m.s. & $\mathrm{F}$ & $\mathrm{p}$ & m.s. & $\mathrm{F}$ & $\mathrm{p}$ \\
\hline Light & 1 & 1.571 & 14.208 & $0.001^{*}$ & 1.242 & 34.834 & $0.000^{*}$ & 0.536 & 18.223 & $0.000^{*}$ \\
\hline Microcosm & 1 & 1.042 & 9.422 & $0.006^{*}$ & 0.038 & 1.070 & 0.313 & 0.006 & 0.206 & 0.655 \\
\hline Light $\times$ Microcosm & 1 & 0.141 & 1.276 & 0.272 & 0.127 & 3.566 & 0.074 & 0.064 & 2.194 & 0.154 \\
\hline Residual & 20 & 0.111 & & & 0.036 & & & 0.029 & & \\
\hline Total & 23 & & & & & & & & & \\
\hline
\end{tabular}

2 days (Fig. 6). The highest values for 2-D redistribution were observed at the termination of the tracer incubation (Li/Da-I, $3.54 \pm$ $0.69 \mathrm{~cm}^{2}$, Dark-I, $\left.2.85 \pm 0.83 \mathrm{~cm}^{2}\right)$. Control aquaria were similar at the termination of the experiment (light/dark cycles: $1.06 \pm 0.12 \mathrm{~cm}^{2}$ and darkness: $1.08 \pm 0.11 \mathrm{~cm}^{2}$ ) with lower values compared to aquaria with fauna. The difference between 2-D redistribution under light/dark compared to dark conditions was not significantly different for the faunal aquaria ( $\mathrm{t}$-test, $\mathrm{p}=0.328$ ).

Averaged over the experimental period, the daily transport was $1.7 \pm 0.4 \mathrm{~cm}^{2} \mathrm{~d}^{1}$ during light/dark (Li/Da-I) and $1.3 \pm 0.5 \mathrm{~cm}^{2} \mathrm{~d}^{1}$ during dark (Dark-I) conditions. After 10 days of incubation, the total area of luminophore relocalization (i.e. the integrated transport) in aquaria with fauna corresponded to $16.9 \pm 2.3 \mathrm{~cm}^{2}$ during light/dark and $12.9 \pm 3.0 \mathrm{~cm}^{2}$ during dark conditions (Fig. 7). For the controls, the integrated transport was lower and values were similar in light/dark $\left(5.5 \pm 0.8 \mathrm{~cm}^{2}\right)$ and dark $\left(6.5 \pm 1.8 \mathrm{~cm}^{2}\right)$ conditions at the termination of the tracer incubation. The rate of luminophore transport was calculated from a linear fit of the integrated transport with time of incubation $\left(\delta\left(\sum \mathrm{M}_{\mathrm{i}}\right) / \delta \mathrm{t} ; \mathrm{R}^{2}=0.9899\right.$ to 0.9996$)$. Under light/dark conditions, rates were slightly higher compared to dark conditions (1.66 $\pm 0.21 \mathrm{~cm}^{2} \mathrm{~d} \quad{ }^{1}$ and, $1.25 \pm 0.28 \mathrm{~cm}^{2} \mathrm{~d}^{1}$, respectively), although the difference was not significant ( $t$-test, $\mathrm{p}=0.117$ ).

\subsection{The biodiffusion $\left(D_{b}\right)$ and non-local transport $(r)$ coefficients}

The transport coefficients were generally higher in the light/dark treatment as compared to the dark treatment (Fig. 8). $\mathrm{D}_{\mathrm{b}}$ in microcosms exposed to light/dark cycles (Li/Da-C, $1.37 \pm 0.41 \mathrm{~cm}^{2} \mathrm{y}^{1}$, and Li/Da-A, $1.08 \pm 0.56 \mathrm{~cm}^{2}$ y ${ }^{1}$ ) was significantly (2-way ANOVA, Table 2) higher compared to the dark microcosms (Dark-C, $0.96 \pm$
$0.34 \mathrm{~cm}^{2} \mathrm{y}^{1}$, and Dark-A, $0.46 \pm 0.40 \mathrm{~cm}^{2} \mathrm{y}^{1}$ ). There was also a significant difference in $D_{b}$ between types of microcosms, with higher values in the cores. The imaging technique supported a higher $D_{b}$ under light/dark (Li/Da-I; $1.81 \pm 0.01 \mathrm{~cm}^{2} \mathrm{y}^{1}$ ) compared to dark (Dark-I; $1.31 \pm 0.44 \mathrm{~cm}^{2} \mathrm{y}^{1}$ ) conditions.

The non-local transport coefficient, $r$, was also significantly higher under light/dark conditions (Li/Da-C, $4.39 \pm 2.40 \mathrm{y}{ }^{1}$ and Li/Da-A, $4.56 \pm 3.12 y^{1}$, 2-way ANOVA, Table 2) compared to dark conditions (Dark-C, $1.75 \pm 1.62 \mathrm{y}^{1}$, and Dark-A, $0.26 \pm 0.26 \mathrm{y}^{1}$ ). There was no statistical difference between types of microcosms. Model predictions to estimate $D_{b}$ and $r$ were in good agreement with experimental data and the distribution patterns of luminophores (error ranged between 1.06 and 5.89). In Li/Da-I, $r$ was also slightly higher than in Dark-I $\left(4.06 \pm 4.32 \mathrm{y}^{1}\right.$ compared to $\left.2.41 \pm 4.01 \mathrm{y}^{1}\right)$, but the variability was high (Fig. 8).

\section{Discussion}

\subsection{Distribution of luminophores}

H. diversicolor has been observed to construct semi-permanent $\mathrm{U}$, Y- or J-shaped mucous-lined burrows that can extend about $20 \mathrm{~cm}$ deep into the sediment (Davey, 1994; Esselink and Zwarts, 1989). The particle transport induced by $\mathrm{H}$. diversicolor is characterized as mainly diffusive in the surface layer while non-local in deeper sediment layers (François et al., 2002). The general distribution of luminophores obtained in the present study confirmed an exponential decrease of luminophores with depth over the first $\sim \mathrm{cm}$ and subsurface peaks of the tracer at depth (Figs. 2 and 4). Similar distribution patterns were observed in aquaria and cores exposed to $12 \mathrm{~h}$ light/dark cycles. The i)

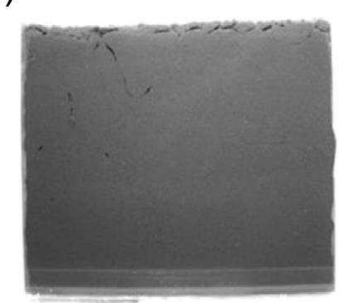

ii)

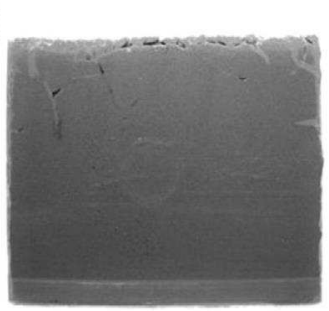

iii)

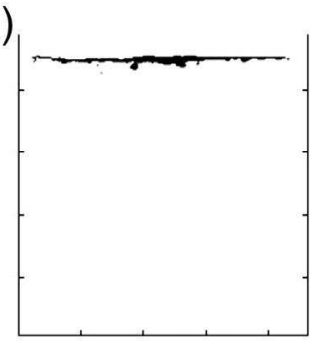

iv)

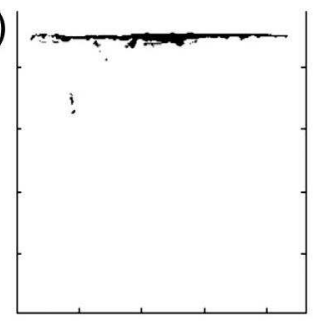

v)
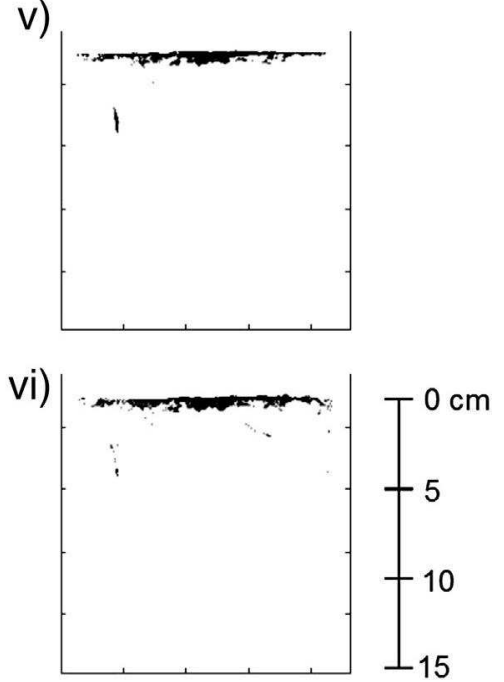

Fig. 4. Examples of sediment reworking patterns by Hediste diversicolor (i and ii) and time-resolved distributions of fluorescent particles (luminophores) following particle displacements during sediment water incubations in glass aquaria (iii vi). Images were captured 2 days before (i) and 10 days after (ii) the addition of luminophores under normal light conditions and without bandpass-filters to visualize the burrows. Images of fluorescence were thresholded before quantification of reworking patterns $1 \mathrm{~h}$ (iii), $8 \mathrm{~h}$ (iv), $24 \mathrm{~h} \mathrm{(v)} \mathrm{and} 10$ days (vi) after addition of luminophores. The circular shape in image ii is a camera reflection. 


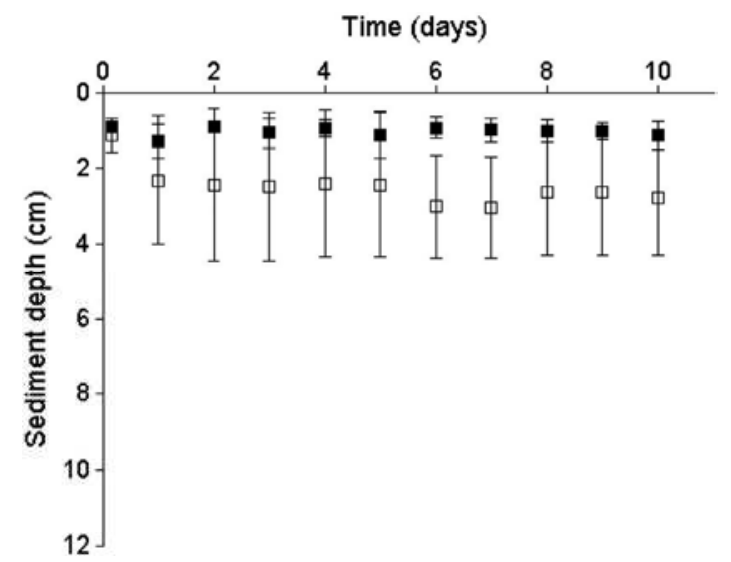

Fig. 5. Maximum penetration depth of luminophores (MPD) with time during sediment water incubations. Luminophore distributions were quantified by side-view imaging of fluorescence in aquaria with Hediste diversicolor exposed to light/dark (open symbols) and dark conditions (filled symbols). Values are mean $\pm \mathrm{SD}(\mathrm{n}=3)$.

relative amount of luminophores found in the subsurface peaks was, however, lower under darkness compared to light/dark cycles. Fewer luminophores were also recovered in the subsurface peaks in the aquaria compared to the cores. It therefore seemed that the final distribution of luminophores depended on the light conditions as well as the type of microcosm.

Visual inspections and calculated proxies quantitatively and qualitatively used to describe particle reworking (luminophore distributions, $\mathrm{D}_{\mathrm{b}}, \mathrm{r}, \mathrm{MPD}, 2-\mathrm{D}$ redistribution and transport rates), confirmed no significant displacement of particles in the control cores or the control aquaria. Indications of small-scale transport of luminophores to a maximum depth of $\sim 1 \mathrm{~cm}$ were most probably due to activities by small fauna.

It appeared that temporal patterns in the redistribution of luminophores by $\mathrm{H}$. diversicolor could be described in at least two phases (Figs. 5 and 6). During the initial phase of 12 days there was a pronounced change in the 2-D redistribution and the MPD. The transport and removal of particles from the thin layer of luminophores initially deposited on the sediment surface were associated with a logarithmic increase in the 2-D redistribution and a rapid transport of surface luminophores deeper into the sediment. After 2 days, the redistribution of particles reached $6470 \%$ of its final value and the progressive increase leveled off. In parallel, following this initial phase the MPD was fairly stable until the end of the tracer incubation. The integrated transport revealed a rather constant daily relocation of luminophores by $\mathrm{H}$. diversicolor during the

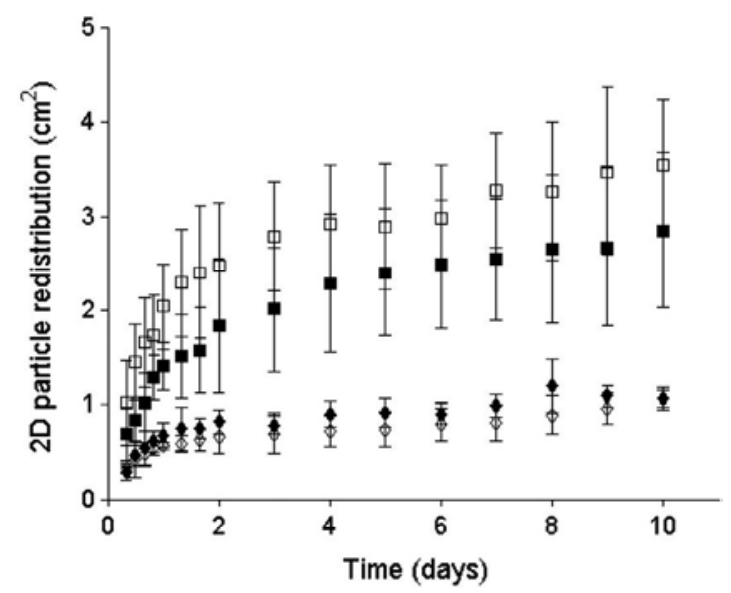

Fig. 6. 2-D redistribution of particles with time in the presence of Hediste diversicolor (squares) or controls (diamonds) in aquaria exposed to light/dark (open symbols) and dark (filled symbols) conditions. Values are mean $\pm \mathrm{SD}(\mathrm{n}=3)$.

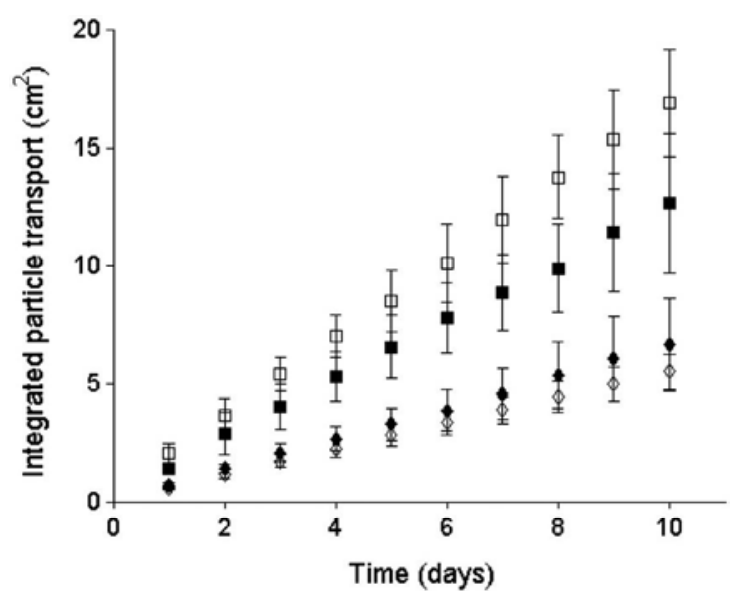

Fig. 7. Integrated particle transport in the presence of Hediste diversicolor (squares) or controls (diamonds) as identified by side-view imaging of fluorescence under light/dark (open symbols) and dark (filled symbols) conditions. Values are mean $\pm \mathrm{SD}(\mathrm{n}=3)$.

tracer incubation in all aquaria (Fig. 7). This was interpreted as a constant particle reworking behavior by the polychaete throughout the experimental period. This is in agreement with the study by Davey (1994), where imaging by X-radiography progressively demonstrated complex burrow constructions by $\mathrm{H}$. diversicolor over a three week long experimental period.

\subsection{Methodological considerations}

Thin aquaria have frequently been used as experimental systems to study particle reworking by single-species (Maire et al., 2006; Piot et al., 2008; Schiffers et al., 2011) or natural communities (Gilbert et al., 2003; Solan et al., 2004), likely as a result of the development of the fluorescence imaging technique. Introducing bioturbating macrofauna to thin aquaria is a technique associated with potential artifacts mainly related to changes in behavior due to wall effects and alterations in the physical geometry of the sediment matrix (Dorgan et al., 2006). In addition, the number of individuals added to experimental microcosms often differs within the experiment due to normalization of e.g. biomass, biovolume or density between treatments (Gilbert et al., 2007; Michaud et al., 2006; Norling et al., 2007).

In this study, additions of $\mathrm{H}$. diversicolor varied between cores (4 ind.) and aquaria ( 1 ind.). This was a direct consequence of the desire to maintain a similar density (ind. $\mathrm{m}^{2}$ ) despite an $\sim 4$ times smaller surface area in the aquaria than in the cores. Thus, both the type of microcosm and potential interactions between individuals should be considered when comparing the obtained reworking proxies for cores and aquaria. A possible consequence of the difference in actual number of $\mathrm{H}$. diversicolor in cores and aquaria relates to an increased complexity of the burrow system in aquaria with single individuals (Davey, 1994). For example, a territorial behavior of H. diversicolor including aggressive intraspecific interactions (Esnault et al., 1990) may lower the variation among replicates in Plexiglass cores with several individuals than thin aquaria with a single individual. Further, such behavior may also have influenced reworking proxies, e.g. $D_{\mathrm{b}}$. The overall importance for the complex interactive effects that may have occurred between individuals was, however, not within the scope of the present study. Due to the comparably low density of fauna $\left(\sim 500\right.$ ind. $\left.\mathrm{m}^{2}\right)$, these effects were considered not to have influenced the main conclusions of the study.

$\mathrm{H}$. diversicolor has been documented to preferentially bury along walls under experimental conditions (Davey, 1994). Individuals were therefore expected to preferentially create burrows along the side of the walls in both types of microcosms. The wall area normalized to sediment volume was larger in the aquaria compared to the cores $\left(1.6 \mathrm{~cm}{ }^{1}\right.$ compared to $\left.0.4 \mathrm{~cm}^{1}\right)$. A larger ratio between wall area 

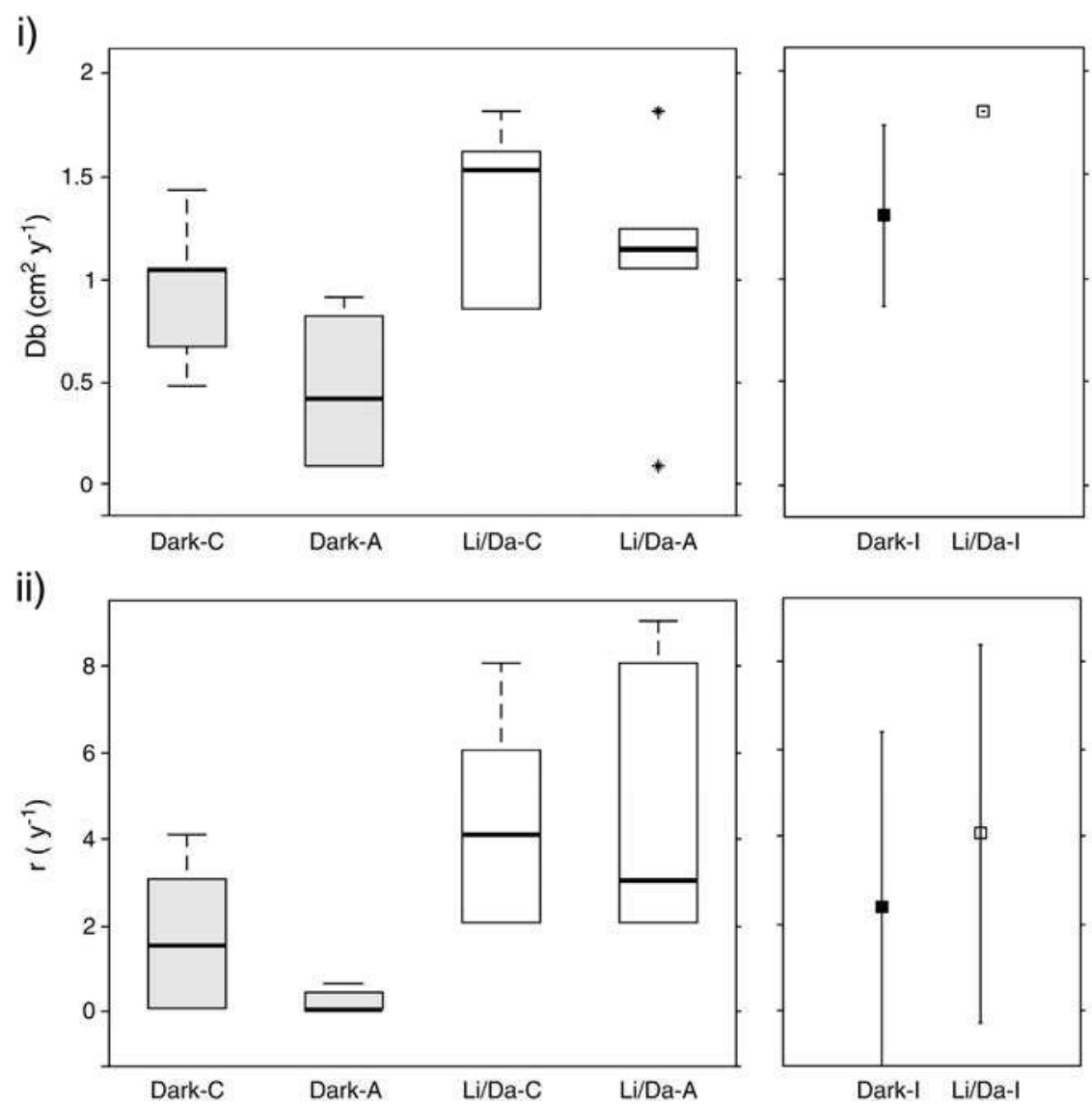

Fig. 8. The biodiffusion coefficient $\left(D_{b}\right)(i)$, and the non-local transport coefficient (r) (ii) for Hediste diversicolor during sediment water incubations in Plexiglass cores (C) and thin aquaria (A). Reworking variables were quantified from sectioning (left), or from side-view imaging (right). Incubations were performed under light/dark (Li/Da-C, Li/Da-A and Li/Da-I) and dark (Dark-C, Dark-A and Dark-I) conditions. Boxplots $(\mathrm{n}=6)$ demonstrate the median and the 25th and 75th percentiles (edges of the box) of the data set. The whiskers extend to the most extreme data points not considered as outliers. Outliers $\left(\mathrm{D}_{\mathrm{b}}, \mathrm{Li} / \mathrm{Da}-\mathrm{A}\right)$ are indicated by an asterisk. Reworking variables quantified by the imaging technique are represented as mean $\pm \operatorname{SD}(\mathrm{n}=3)$.

and sediment volume in the aquaria than in the cores could have stimulated animal activities and particle reworking close to the wall of the aquaria. Of the three measured particle reworking proxies, there were significant differences between the two types of microcosms only for $D_{b}$. However, $D_{b}$ was lower in the aquaria compared to the cores. In contrast to a stimulated activity in aquaria, it therefore seemed that the observed difference in particle reworking was mainly caused by a restriction in lateral movements in the thin aquaria rather than by general wall effects.

\subsection{Effects from light exposure on reworking activities of $\mathrm{H}$. diversicolor}

H. diversicolor inhabits the littoral zone and is naturally exposed to pronounced variations of environmental conditions (e.g. light, temperature, salinity, availability of oxygen and organic material (Möller, 1985; Rasmussen and Jorgensen, 1992). In temperate regions such as the west coast of Sweden, the diurnal availability and variations in light intensity over the year can be expected to be important factors for the reworking behavior of $\mathrm{H}$. diversicolor. In the present study, all measured proxies for particle reworking demonstrated a general decrease in transport of luminophores in darkness compared to light/dark cycles. The difference was more pronounced using the sectioning compared to the imaging technique. This discrepancy was probably caused by the low number of replicates for the latter technique, rather than an indication of similar reworking proxies between the two light treatments using imaging.

From imaging it was discerned that rates of particle transport were $30 \%$ higher during the light/dark cycles compared to darkness (Fig. 7). There appeared to be no difference in the long-term behavior of the $\mathrm{H}$. diversicolor in the light/dark cycles compared to darkness as the daily particle transport was constant over the duration of the experiment, only the magnitude was affected. This reduced reworking activity under dark conditions could be explained by direct lighttriggered behavior. Indeed, a pulsed and temporarily enhanced transport of surface deposited particles into the sediment and burrow systems occurs normally during prospecting/foraging for food on the sediment surface. Assuming that luminophores were transported into the sediment mainly during surface feeding, the general lower values of particle reworking proxies in the dark treatment would be associated with a decreased surface feeding by $\mathrm{H}$. diversicolor in the darkness compared to light/dark cycles. It has been suggested that $\mathrm{H}$. diversicolor has a diurnal feeding rhythm and preferentially feed on the surface during the day (Lambert et al., 1992). It was further shown that the worm kept the feeding rhythm even if the light was turned off for $24 \mathrm{~h}$ (Lambert et al., 1992). Food prospecting would be governed by an endogenous diurnal rhythm. In contrast to this observed diurnal surface feeding, Wenzhöfer and Glud (2004) related a dramatic increase in oxygen consumption to increased surface activities by $\mathrm{H}$. diversicolor at sunset. In support of this conclusion, Tang and Kristensen (2007) found that ventilation activity by $\mathrm{H}$. diversicolor decreased significantly during the night and inferred this behavior to nocturnal surface feeding similar to that of Alitta (Nereis) virens (Caron et al., 2004; Last, 2003; Miron et al., 1992). Although somewhat conflicting observations on the response, a bioturbation behavior directly coupled to and possibly triggered by the availability of light has therefore been demonstrated in several investigations. In this study, the lower rates of both biodiffusive and non-local transport observed over 10 days indicated a lower activity by $\mathrm{H}$. diversicolor in the upper surface layer $(02 \mathrm{~cm})$ 
under dark conditions. It also suggested a decreased activity between the deeper burrows $(26 \mathrm{~cm})$ and the surface sediment. In addition to the decreased non-local transport, the shallower MPD supported a decreased activity at depth under dark conditions (Fig. 3). Depth of burrow constructions has been correlated to body conditions where worms in good condition are able to maintain deeper burrows (Esselink and Zwarts, 1989). Shallower burrows could therefore be a sign of stress and worm activity under non-optimal conditions in the dark treatment.

Besides the direct effect of light on the feeding behavior of $\mathrm{H}$. diversicolor, feeding characteristics are also indirectly affected by light through the diurnal activities by benthic microalgae. H. diversicolor is known to feed on benthic diatoms (Tang and Kristensen, 2007) and a possible decrease in the availability and amount of food in the dark treatment would also decrease particle reworking activities by H. diversicolor (Nogaro et al., 2008).

These observations of a light dependent particle reworking behavior by H. diversicolor may have direct implications for the biogeochemistry and element cycling in surface sediments. For example, during the day, surface sediments in shallow-water environments are oxidized by benthic microalgae during photosynthesis (Revsbech and Jorgensen, 1983). Under oxidizing sediment conditions, Fe and Mn predominately occur as particulate $\mathrm{Fe}(\mathrm{III})$ - and $\mathrm{Mn}(\mathrm{IV})$-oxides rather than $\mathrm{Fe}^{2+}$ and $\mathrm{Mn}^{2+}$ dissolved in the pore water (Froelich et al., 1979). In addition to the particle redistribution and enhanced transport of e.g. organic material to deeper sediment layers, the transport of particulate $\mathrm{Fe}$ - and Mn-oxides across redox boundaries may therefore under diurnal variations in light conditions be enhanced in sediments inhabited by $\mathrm{H}$. diversicolor. Such transport of reactants across redox zones and the exposure of organic material to a suite of oxidants have been found to stimulate rates and extent of organic matter mineralization and thus reduce the fraction of organic material that is buried in the sedimentary record (Aller, 1994; Hulthe et al., 1998; Sun et al., 2002).

\section{Conclusions}

Imaging of luminophores was proven to be a successful technique to quantify time-resolved particle reworking by H. diversicolor. Overall, patterns of particle translocation from imaging agreed with results from the destructive sampling protocols. The main advantage using the imaging technique was the ability to quantify particle reworking and estimate reworking proxies throughout the incubation. This feature allowed time-resolved quantification of 2-D particle redistribution (small variation after $\sim 2$ days), MPD (reached an asymptotic value after $\sim 12$ days), and daily transport rates (constant throughout the incubation) with spatial resolution better than $80 \mu \mathrm{m}$ pixel ${ }^{1}$.

The influence of light/dark cycles and constant darkness on reworking activities by $\mathrm{H}$. diversicolor was consistent in the two microcosm types (Plexiglass cores and thin glass aquaria). However while the non-local transport and MPD were statistically similar between microcosms, the biodiffusion coefficient was significantly lower in the aquaria compared to the cores. The reworking behavior of $\mathrm{H}$. diversicolor was therefore likely affected by the type of microcosm.

The sediment reworking behavior by $\mathrm{H}$. diversicolor was significantly affected by the light treatments with generally lower values of $D_{b}, r$, and MPD during the darkness compared to the light/dark cycles. The rate of particle transport was constant during the 10 day incubation period, and rates were $~ 30 \%$ lower in the darkness compared to the light/dark cycles. Observations were suggested to be associated with a decreased surface feeding by $\mathrm{H}$. diversicolor.

\section{Acknowledgments}

This study was financially supported by the Swedish Research Council (VR) and the Swedish Research Council for Environment Agricultural Sciences and Spatial Planning (FORMAS). Karl Norling assisted during field experiments. The present contribution was improved by comments from two anonymous reviewers. This is Nereis Park contribution number 33. ST

\section{References}

Aller, R.C., 1982. The effects of macrobenthos on chemical properties of marine sediment and overlying water. In: McCall, P.L., Tavesz, M.J.S. (Eds.), Animal Sediment Relations. Plenum Press, New York, pp. 53102.

Aller, R.C., 1994. Bioturbation and remineralization of sedimentary organic matter: effects of redox oscillation. Chem. Geol. 114 (3 4), 331345.

Berner, R.A., 1980. Early Diagenesis: A Theoretical Approach. Princeton University Press, Princeton, USA (241 pp.).

Boudreau, B.P., 1986. Mathematics of tracer mixing in sediments: I. Spatially-dependent diffusive mixing. Am. J. Sci. 286 (3), 161198

Boudreau, B.P., 1997. Diagenetic Models and Their Implementation. Springer-Verlag Berlin, Heidelberg New York (414 pp.)

Caron, A., Desrosiers, G., Olive, P.J.W., Retière, C., Nozais, C., 2004. Comparison of diet and feeding activity of two polychaetes, Nephtys caeca (Fabricius) and Nereis virens (Sars), in an estuarine intertidal environment in Québec, Canada. J. Exp. Mar. Biol. Ecol. 304 (2), 225242

Davey, J.T., 1994. The architecture of the burrow of Nereis diversicolor and its quantification in relation to sediment water exchange. J. Exp. Mar. Biol. Ecol. 179 (1), 115129.

Dorgan, K.M., Jumars, P.A., Johnson, B.D., Boudreau, B.P., 2006. Macrofaunal burrowing the medium is the message. In: Gibson, R.N., Atkinson, R.J.A., Gordon, J.D.M. (Eds.), Oceanography and Marine Biology An Annual Review, vol. 44. Crc Press-Taylor \& Francis Group, Boca Raton, pp. 85121.

Duport, E., Stora, G., Tremblay, P., Gilbert, F., 2006. Effects of population density on the sediment mixing induced by the gallery-diffusor Hediste (Nereis) diversicolor O.F. Muller, 1776. J. Exp. Mar. Biol. Ecol. 336 (1), 3341.

Engelsen, A., Hulth, S., Pihl, L., Sundbäck, K., 2008. Benthic trophic status and nutrien fluxes in shallow-water sediments. Estuarine Coastal Shelf Sci. 78 (4), 783795.

Esnault, G., Retière, C., Lambert, R., Esnault, G., Retière, C., Lambert, R., 1990. Food resource partitioning in a population of Nereis diversicolor (Annelida, Polychaeta) under experimental conditions. In: Barnes, M., Gibson, R.N. (Eds.), Trophic Relationships in the Marine Environment. Proc. 24th Europ. Mar. Biol. Symp. Aberdeeen University Press, pp. 453467.

Esselink, P., Zwarts, L., 1989. Seasonal trend in burrow depth and tidal variation in feeding activity of Nereis diversicolor. Mar. Ecol. Prog. Ser. 56 (3), 243254.

Fisher, J.B., McCall, P.L., Robbins, J.A., 1980. Vertical mixing of lake sediments by tubificid oligochaetes. J. Geophys. Res. 85 (C7), 39974006.

Francois, F., Poggiale, J.C., Durbec, J.P., Stora, G. 1997. A new approach for the modelling of sediment reworking induced by a macrobenthic community. Acta Biotheor. 45 (3 4), 295319

François, F., Gerino, M., Stora, G., Durbec, J.-P., Poggiale, J.-C., 2002. Functional approach to sediment reworking by gallery-forming macrobenthic organisms: modeling and application with the polychaete Nereis diversicolor. Mar. Ecol. Prog. Ser. 229, 127136.

Froelich, P.N., Klinkhammer, G.P., Bender, M.L., Luedtke, N.A., Heath, G.R., Cullen, D. Dauphin, P., Hammond, D., Hartman, B., Maynard, V., 1979. Early oxidation of organic matter in pelagic sediments of the eastern equatorial Atlantic: suboxic diagenesis. Geochim. Cosmochim. Acta 43 (7), 10751090.

Gilbert, F., Hulth, S., Strömberg, N., Ringdahl, K., Poggiale, J.C., 2003. 2-D optical quantification of particle reworking activities in marine surface sediments. J. Exp. Mar. Biol. Ecol. 285, 251263.

Gilbert, F., Hulth, S, Grossi, V., Poggiale, J.-C., Desrosiers, G, Rosenberg R., Gérino, M. François-Carcaillet, F., Michaud, E., Stora, G., 2007. Sediment reworking by marine benthic species from the Gullmar Fjord (Western Sweden): importance of faunal biovolume. J. Exp. Mar. Biol. Ecol. 348 (1 2), 133144.

Goldberg, E.D., Koide, M., 1962. Geochronological studies of deep sea sediments by the ionium/thorium method. Geochim. Cosmochim. Acta 26, 417450 (MAR).

Guinasso, N.L. Schink, D.R, 1975. Quantitative estimates of biological mixing rates in abyssal sediments. J. Geophys. Res. Oceans Atmos. 80 (21), 30323043.

Hedman, J.E., Gunnarsson, J.S., Samuelsson, G., Gilbert, F., 2011. Particle reworking and solute transport by the sediment-living polychaetes Marenzelleria neglecta and Hediste diversicolor. J. Exp. Mar. Biol. Ecol. 407 (2), 294301.

Hughes, R.G., Lloyd, D., Ball, L., Emson, D., 2000. The effects of the polychaete Nereis diversicolor on the distribution and transplanting success of Zostera noltii. Helgol. Mar. Res. 54 (2 3), 129136.

Hulthe, G., Hulth, S., Hall, P.O.J., 1998. Effect of oxygen on degradation rate of refractory and labile organic matter in continental margin sediments. Geochim. Cosmochim. Acta 62 (8), 13191328

Kristensen, E., Andersen, F.O., Blackburn, T.H., 1992. Effects of benthic macrofauna and temperature on degradation of macroalgal detritus: the fate of organic carbon. Limnol. Oceanogr. 37 (7), 14041419.

Kristensen, E., Penha-Lopes, G., Delefosse, M., Valdemarsen, T., Quintana, C.O., Banta G.T., 2012. What is bioturbation? The need for a precise definition for fauna in aquatic sciences. Mar. Ecol. Prog. Ser. 446, 285302.

Lagauzere, S., Coppin, F., Gerino, M., Delmotte, S., Stora, G., Bonzom, J.M., 2011. An alternative method of particulate fluorescent tracer analysis in sediments using microplate fluorimeter. Environ. Technol. 32 (5), 551560.

Lambert, R., Desrosiers, G., Retiere, C., Miron, G., 1992. Activité de prospection de son aire d'alimentation par la polychète Nereis diversicolor (O.F. Müller): données préliminaires. Cah. Biol. Mar. 33 (1), 4354. 
Last, K.S., 2003. An actograph and its use in the study of foraging behaviour in the benthic polychaete, Nereis virens Sars. J. Exp. Mar. Biol. Ecol. 287 (2), 237248.

Lecroart, P., Maire, O., Schmidt, S., Gremare, A., Anschutz, P., Meysman, F.J.R., 2010. Bioturbation, short-lived radioisotopes, and the tracer-dependence of biodiffusion coefficients. Geochim. Cosmochim. Acta 74 (21), 60496063.

Maire, O., Duchene, J.C., Rosenberg, R., de Mendonca, J.B., Gremare, A., 2006. Effects of food availability on sediment reworking in Abra ovata and A. nitida. Mar. Ecol. Prog. Ser. 319, 135153.

Maire, O., Lecroart, P., Meysman, F., Rosenberg, R., Duchene, J.C., Gremare, A., 2008. Quantification of sediment reworking rates in bioturbation research: a review. Aquat. Biol. 2 (3), 219238.

Mermillod-Blondin, F., Rosenberg, R., François-Carcaillet, F., Norling, K., Mauclaire, L., 2004. Influence of bioturbation by three benthic infaunal species on microbial communities and biogeochemical processes in marine sediment. Aquat. Microb. Ecol. 36 (3), 271284

Meysman, F.J.R., Boudreau, B.P., Middelburg, J.J., 2003. Relations between local, discrete and continuous models of bioturbation. J. Mar. Res. 61, 391410.

Meysman, F.J.R., Boudreau, B.P., Middelburg, J.J., 2010. When and why does bioturbation lead to diffusive mixing? J. Mar. Res. 68 (6), 881920.

Michaud, E., Desrosiers, G., Mermillod-Blondin, F., Sundby, B., Stora, G., 2006. The functional group approach to bioturbation: II. The effects of the Macoma balthica community on fluxes of nutrients and dissolved organic carbon across the sediment water interface. J. Exp. Mar. Biol. Ecol. 337 (2), 178189.

Miron, G., Desrosiers, G., Retiere, C., Masson, S., 1992. Variations in time budget of the polychaete Nereis virens as a function of density and acclimation after introduction to a new burrow. Mar. Biol. 114 (1), 4148.

Möller, P., 1985. Production and abundance of juvenile Nereis diversicolor, and oogenic cycle of adults in shallow waters of western Sweden. J. Mar. Biol. Assoc. U. K. 65 (3), 603616.

Nizzoli, D., Bartoli, M., Cooper, M., Welsh, D.T., Underwood, G.J.C., Viaroli, P., 2007. Implications for oxygen, nutrient fluxes and denitrification rates during the early stage of sediment colonisation by the polychaete Nereis spp. in four estuaries, Estuarine Coastal Shelf Sci. 75 (1 2), 125134.

Nogaro, G., Charles, F., de Mendonca, J.B., Mermillod-Blondin, F., Stora, G., FrancoisCarcaillet, F., 2008. Food supply impacts sediment reworking by Nereis diversicolor. Hydrobiologia 598, 403408.

Nordström, M., Bonsdorff, E., Salovius, S., 2006. The impact of infauna (Nereis diversicolor and Saduria entomon) on the redistribution and biomass of macroalgae on marine soft bottoms. J. Exp. Mar. Biol. Ecol. 333 (1), 5870

Norling, K., Rosenberg, R., Hulth, S., Grémare, A., Bonsdorff, E., 2007. Importance of functional biodiversity and species specific traits of benthic fauna for ecosystem functions in marine sediments. Mar. Ecol. Prog. Ser. 332, 1123.

Papaspyrou, S., Thessalou-Legaki, M., Kristensen, E., 2010. The influence of infaunal (Nereis diversicolor) abundance on degradation of organic matter in sandy sediments. J. Exp. Mar. Biol. Ecol. 393 (1 2), 148157.
Pihl, L., Rosenberg, R., 1982. Production, abundance, and biomass of mobile epibenthic marine fauna in shallow waters, western Sweden. J. Exp. Mar. Biol. Ecol. 57 (2 3), 273301.

Piot, A., Rochon, A., Stora, G., Desrosiers, G., 2008. Experimental study on the influence of bioturbation performed by Nephtys caeca (Fabricius) and Nereis virens (Sars) annelidae on the distribution of dinoflagellate cysts in the sediment. J. Exp. Mar. Biol. Ecol. 359 (2), 92101

Quinn, G.P., Keough, M.J., 2002. Experimental Design and Data Analysis for Biologists, Cambridge, UK.

Rasmussen, H., Jorgensen, B.B., 1992. Microelectrode studies of seasonal oxygenuptake in a coastal sediment role of molecular-diffusion. Mar. Ecol. Prog. Ser. 81 (3), 289303.

Revsbech, N.P., Jorgensen, B.B., 1983. Photosynthesis of benthic microflora measured with high spatial resolution by the oxygen microprofile method: capabilities and limitations of the method. Limnol. Oceanogr. 28 (4), 749756.

Rhoads, D.C., 1974. Organism sediment relations on the muddy sea floor. Oceanogr. Mar. Biol. Annu. Rev. 12, 263300

Scaps, P., 2002. A review of the biology, ecology and potential use of the common ragworm Hediste diversicolor (OF Muller) (Annelida: Polychaeta). Hydrobiologia 470 (1 3), 203218.

Schiffers, K., Teal, L.R., Travis, J.M.J., Solan, M., 2011. An open source simulation model for soil and sediment bioturbation. PLoS One 6 (12), e28028.

Smith, J.N., Boudreau, B.P., Noshkin, V., 1986. Plutonium and ${ }^{210} \mathrm{~Pb}$ distributions in northeast Atlantic sediments: subsurface anomalies caused by non-local mixing. Earth Planet. Sci. Lett. 81 (1), 1528

Solan, M., Wigham, B.D., Hudson, I.R., Kennedy, R., Coulon, C.H., Norling, K., Nilsson, H.C., Rosenberg, R., 2004. In situ quantification of bioturbation using time-lapse fluorescent sediment profile imaging (f-SPI), luminophore tracers and model simulation. Mar. Ecol. Prog. Ser. 271, 112

Sun, M.-Y.i, Aller, R.C., Lee, C., Wakeham, S.G., 2002. Effects of oxygen and redox oscillation on degradation of cell-associated lipids in surficial marine sediments. Geochim. Cosmochim. Acta 66 (11), 20032012.

Tang, M., Kristensen, E., 2007. Impact of microphytobenthos and macroinfauna on temporal variation of benthic metabolism in shallow coastal sediments. J. Exp. Mar. Biol. Ecol. 349 (1), 99112.

Thevenaz, P., Ruttimann, U.E., Unser, M., 1998. A pyramid approach to subpixel registration based on intensity. IEEE Trans. Image Process. 7 (1), 2741.

Vedel, A., Andersen, B.B., Riisgard, H.U., 1994. Field investigations of pumping activity of the facultatively filter-feeding polychaete Nereis diversicolor using an improved infrared phototransducer system. Mar. Ecol. Prog. Ser. 103 (1 2), 91101.

Wenzhöfer, F., Glud, R.N., 2004. Small-scale spatial and temporal variability in coastal benthic O-2 dynamics: effects of fauna activity. Limnol. Oceanogr. 49 (5), 14711481

Wheatcroft, R.A. Jumars, P.A. Smith, C.R., Nowell, A.R.M., 1990. A mechanistic view of the particulate biodiffusion coefficient step lengths, rest periods and transport directions. J. Mar. Res. 48 (1), 177207. 